Article

\title{
Power Quality and Harmonic Analysis of End User Devices
}

\author{
Alberto Dolara * and Sonia Leva \\ Department of Energy, Politecnico di Milano, Via La Masa 34, Milan 20156, Italy; \\ E-Mail: sonia.leva@polimi.it \\ * Author to whom correspondence should be addressed; E-Mail: alberto.dolara@mail.polimi.it; \\ Tel.: +39-02-2399-3829; Fax: +39-02-2399-8566.
}

Received: 8 October 2012; in revised form: 13 December 2012 / Accepted: 14 December 2012 / Published: 19 December 2012

\begin{abstract}
Among the non-linear loads used in household, Compact Fluorescent Lamps (CFLs) and LED lamps are becoming more widespread, while incandescent lamps are intended to be replaced by these types of lighting devices. LEDs and CFLs are significantly more efficient and economical than incandescent lamps, and are expected to be used in $100 \%$ of residential lighting in the future. As nonlinear loads, LEDs and CFLs produce highly distorted currents. A large number of customers using LEDs or CFLs for domestic, commercial and industrial lighting could determine important Power Quality problems. The paper reports experimental measurement results regarding Power Quality in indoor lighting systems. The harmonic absorptions of several types of luminaries are analyzed, highlighting the impact behavior of different lamps function of used luminaries' technologies. The recorded harmonic absorption allows characterizing the harmonic spectrum variability of the investigated lamps.
\end{abstract}

Keywords: lamps; energy savings; experimental measurements; harmonics; power quality

\section{Introduction}

The Power Quality (PQ) in electrical systems is regulated by IEC and EN standards, used as reference by the utilities [1-3]. In order to comply with these technical standards, the utilities have to guarantee admissible voltage levels established by the standards, also ensuring the supply continuity; the end-users have to guarantee current absorptions with adequate Power Factor $(P F)$ and reduced harmonic current absorptions. Indeed, an inadequate $P F$ and/or insufficient PQ level dramatically 
increase the power losses in the distribution grid, the voltage drop and the voltage distortion. Power factor correction capacitors are suitable to compensate the reactive power required by linear loads. Non-linear loads, like rectifiers or arc discharge devices such as fluorescent lamp, require filters to reduce their harmonic current injection.

Among the non-linear loads used in household, Compact Fluorescent Lamps (CFLs) and LED lamps are becoming more widespread, while incandescent lamps are intended to be replaced by these types of lighting devices. Although LED lamps work on a completely different principle than CFLs, both need a power supply system enabling their correct operation and both introduce nonlinearities into the electrical grid. Furthermore, dimming devices are usually used to adjust the luminosity of the lamps. As nonlinear loads, CFLs and LEDs produce highly distorted currents.

Therefore, a good understanding of the CFLs and LEDs harmonic production characteristics becomes necessary. Many studies about the PQ issues related to the lighting devices have been addressed to analyze these problems since the 90s [4-7]. They generally estimate through simulations the mutual influence between loads and distribution grid [1-7]. The measurement of device's harmonic absorption represents the preliminary step for the assessment of loads impact on the distribution grid.

Nowadays, this aspect is more important as the growing interest in energy saving determine the replacement of incandescent lamps with more efficient CFLs or LEDs [8-10]. The knowledge of the power and harmonic absorptions of each device influences their right application and management [11-18]. In the present paper, three experimental studies are performed, investigating the power consumptions and harmonic absorptions of different types of indoor luminaries. The first experimental survey regards two indoor LED panels supplied by external DC switched power supply with dimming system [19]. The second experimental survey regards four LED spots with embedded electronic ballast. The third experimental survey regards two CFLs of earlier generation and two CFLs of new generation. In this paper, the lamps are analyzed focusing on their power quality impact (i.e., produced harmonic currents), neglecting the analysis of other characteristics like luminosity, interferences and life-time. The PQ and harmonic analysis will be performed with reference to the indexes reported in the IEEE Trial use standard definitions for measurement of electric power [20].

In the paper, the Section 2 deals with the main PQ indexes. The results of the measurement campaigns are reported in Section 3 where each Subsection describes monitoring equipment characteristics and it summarizes the obtained results, pointing out the power and harmonic absorptions.

\section{Power Quality Analysis}

A power quality analysis has been performed to compare the different luminaries behavior. The absorbed apparent power is decomposed in four different parts, as described in [20] with regards to the single-phase case. The RMS values of voltage and current are decomposed, respectively, as:

$$
\begin{gathered}
V^{2}=V_{1}^{2}+V_{H}^{2} \\
I^{2}=I_{1}^{2}+I_{H}^{2}
\end{gathered}
$$

where subscript 1 refers to the fundamental harmonic and subscript $H$ refers to all the other harmonics.

The total harmonic distortion, or THD, of a signal is a dimensionless index of the harmonic distortion present and it is defined, for current and voltage respectively, as: 


$$
\begin{aligned}
& T H D_{V}=\frac{V_{H}}{V_{1}} \\
& T H D_{I}=\frac{I_{H}}{I_{1}}
\end{aligned}
$$

Starting from Equations (1) and (2), the apparent power is decomposed into fundamental apparent power $S_{l}$, current distortion power $D_{I}$, voltage distortion power $D_{V}$, and harmonic apparent power $S_{H}$ as:

$$
\begin{gathered}
S_{1}=V_{1} \cdot I_{1} \\
D_{I}=V_{1} \cdot I_{H} \\
D_{V}=V_{H} \cdot I_{1} \\
S_{H}=V_{H} \cdot I_{H}
\end{gathered}
$$

Fundamental apparent power is composed of the fundamental active and reactive powers:

$$
S_{1}^{2}=P_{1}^{2}+Q_{1}^{2}
$$

and accounts the power quantities related to the voltage and current fundamental harmonic.

Current distortion power is related to the product of the voltage fundamental harmonic with all the current harmonic components. Similarly, voltage distortion power is related to the product of the current fundamental harmonic with all the voltage harmonic components.

Similar to the fundamental apparent power, also the harmonic apparent power is composed by the harmonic active power and harmonic distortion power:

$$
S_{H}^{2}=P_{H}^{2}+D_{H}^{2}
$$

Current distortion power, voltage distortion power and harmonic apparent power are related to the voltage and/or current distortion. Combining them, it is possible to define the non-fundamental apparent power $S_{N}$ defined by:

$$
S_{N}^{2}=D_{I}^{2}+D_{V}^{2}+S_{H}^{2}
$$

With regard to energy conversion, the active power is defined as the mean value over the investigated period of the instantaneous power:

$$
P=\frac{1}{T} \int_{\tau}^{\tau+T} v(t) \cdot i(t) \cdot d t
$$

The fundamental active power $P_{1}$ in Equation (7) is given by:

$$
P_{1}=V_{1} \cdot I_{1} \cdot \cos \varphi_{1}
$$

and harmonic active power $P_{H}$ in Equation (8) is given by:

$$
P_{H}=P-P_{1}
$$

Finally, the power factor is defined as:

$$
P F=\frac{P}{S}
$$


$P F$ represents the ratio of the average power converted by the device - the active power $P$ - and the maximum average power that may be converted - the apparent power $S$-considering the same RMS values of voltage and current. In this context, $P F$ can be considered as an indicator of the quality in the energy conversion. $P F$ values close to 1 indicate that the net transfer of energy to the load is the main energy process, while $P F$ values close to 0 characterize devices in which the energy exchange between load and grid, characterized by a nil net energy flow in a period, is the main energy process. In any way, the PF is not a measure of the efficiency of the device: $P F$ indicates the ratio between the active power and the maximum active power that could be produced by the same RMS voltage and current, while the efficiency is the ratio between the output and input power of the device and it is a measure of the power losses into the device (i.e., in a luminaries, efficiency is the ratio between the radiated power as light and the electrical active power $P$ ).

It is important to underline that the only way to increase the power factor by using passive devices is to place a reactive element (usually a capacitor) in parallel with the load. Indeed, in the case of distorted load, the capacitor can compensate only the reactive power $Q_{1}$. Moreover, capacitor acts like a high pass filter for the harmonic currents, requiring oversizing. Finally, parallel resonance with the line inductance can cause high voltage distortion.

\section{Experimental Section}

Luminaries are generally nonlinear loads connected to the low voltage AC distribution grid. Several light sources, like bulbs, can be connected directly to the AC distribution grid, while other kinds of light sources, like fluorescent lamps or LEDs, require a power supply system (a ballast) to interface them with the electric grid. In any case, the current waveform shows some amount of distortion, depending on the luminaries' technology.

In order to evaluate the luminaries' power absorption in terms of power quality analysis as described in Section 2, an experimental procedure based on the measurement of the voltage and current waveforms at the luminaries' terminals has been developed. Considering that supply of the luminaries is single phase, with voltage of $230 \mathrm{~V}$ RMS and frequency of $50 \mathrm{~Hz}$, the acquisition system adopted for the measurement of the voltage and current waveforms requires:

- A $300 \mathrm{Mhz}$, four channels digital oscilloscope;

- A differential voltage probe;

- A $30 \mathrm{kHz}$ Hall effect current probe.

The oscilloscope uses two channels to sample and store the waveforms, which are subsequently transferred to a PC for processing. In order to reduce the noise, 10 cycles are sampled and the average period is calculated. The sampling frequency is automatically set by the oscilloscope. In the test conditions it is $50 \mathrm{kS} / \mathrm{s}$, allowing a frequency resolution - up to 500th harmonic - high enough for power quality analysis. Voltage differential probe allows to reduce the grid voltage to values compatible with the oscilloscope input, moreover it decouples the supply circuit from the measuring circuit for functional and safety reasons. Also, Hall effect current probe allows to transduce current in supply circuit without electrical connection with the measuring circuit. The luminaries under test are connected to the grid of the laboratory, that is supplied by a switchgear whose short circuit current is 
$10 \mathrm{kA}$. Therefore, because of the low absorption of the luminaries, the voltage waveform across to the supplied load is quite similar to the no load voltage waveform.

The experimental tests have been performed on three different kinds of indoor luminaries:

- LED panels;

- LED spots;

- Compact Fluorescent Lamps.

The details of each experimental test on the investigated indoor lamps are reported. For each performed experiment, the current waveforms and the harmonic spectrum are illustrated.

\subsection{Experimental Tests on LED Panels}

LED panels are lighting devices in which the light source consists of several strips of LEDs placed parallel to the edges of the panel. Light source requires a $12 \mathrm{~V} \mathrm{DC}$ power supply which is provided by an external ballast for each panel. Moreover, a simple control system allows to regulate luminous flux in 10 different steps, managing the ballast DC output voltage with a step down converter. The layout of the test arrangement for LED panels' measurements is shown in Figure 1. Experimental tests have been performed on two of LED panels, with rated specifications:

- Type A: LED panel of $21 \mathrm{~W}$ with $36 \mathrm{~W}$ ballast;

- Type B: LED panel of $49.5 \mathrm{~W}$ with $60 \mathrm{~W}$ ballast.

Figure 1. (a) Test arrangement for LED panels monitoring survey; (b) LED panel during test.

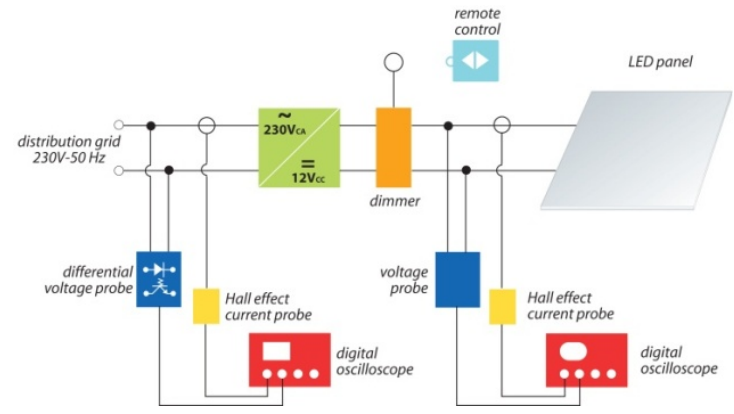

(a)

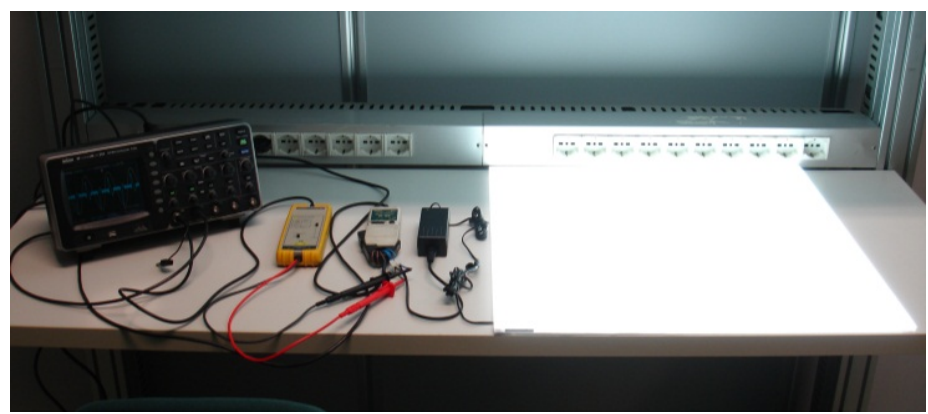

(b)

The tests are performed, for each panel, varying the luminous flux, starting from maximum luminous flux until the minimum luminous flux. The current and voltage measurements are made 5 min after the system is switched on, in order to consider the whole system in a thermal steady state.

The results of the power quality analysis are reported in Table 1 for $21 \mathrm{~W}$ LED panel, respectively in Table 2 for the $49.5 \mathrm{~W}$ LED panel. Considering the large quantity of waveforms, only the most significant results are reported. Figure 2 shows the current waveform and its harmonic spectrum considering the $21 \mathrm{~W}$ LED panel without dimming, while Figure 3 shows the current absorption of the same LED panel when the dimmer is set to step 4. Figure 4 shows the current waveform and its spectrum considering the $49.5 \mathrm{~W}$ LED panel without dimming. In all the cases, the voltage is substantially sinusoidal and voltage first harmonic is shown together with the current waveform. 
Table 1. Power quality analysis of the measurements results for $21 \mathrm{~W}$ LED panel with $36 \mathrm{~W}$ ballast.

\begin{tabular}{|c|c|c|c|c|c|c|c|c|c|c|c|c|c|c|c|c|c|c|c|}
\hline \multirow{2}{*}{ Dimmer } & \multicolumn{4}{|c|}{ Voltage RMS values } & \multicolumn{4}{|c|}{ Current RMS values } & \multirow{2}{*}{$\begin{array}{c}\begin{array}{c}\text { App. } \\
\text { power }\end{array} \\
\text { S } \\
\text { (VA) }\end{array}$} & \multicolumn{3}{|c|}{$\begin{array}{c}\text { Active power } \\
\text { decomposition }\end{array}$} & \multicolumn{5}{|c|}{$\begin{array}{l}\text { Apparent power } \\
\text { decomposition }\end{array}$} & \multirow{2}{*}{$\operatorname{os} \varphi_{1}$} & \multirow{2}{*}{$P F$} \\
\hline & $\begin{array}{c}\mathrm{V} \\
(\mathrm{V})\end{array}$ & $\begin{array}{l}V_{1} \\
(V)\end{array}$ & $\begin{array}{l}\mathbf{V}_{\mathrm{H}} \\
(\mathrm{V})\end{array}$ & THD $_{\mathrm{V}}$ & $\begin{array}{c}\text { I } \\
(\mathbf{m A})\end{array}$ & $\begin{array}{c}\mathbf{I}_{1} \\
(\mathbf{m A})\end{array}$ & $\begin{array}{c}\mathbf{I}_{\mathbf{H}} \\
(\mathbf{m A})\end{array}$ & & & $\begin{array}{c}\mathbf{P} \\
(\mathbf{W})\end{array}$ & $\begin{array}{l}P_{1} \\
(\mathbf{W})\end{array}$ & $\begin{array}{l}\mathbf{P}_{\mathrm{H}} \\
(\mathbf{W})\end{array}$ & $\begin{array}{c}S_{1} \\
(\mathrm{VA})\end{array}$ & $\begin{array}{c}\mathrm{S}_{\mathrm{N}} \\
(\mathrm{VA})\end{array}$ & $\begin{array}{c}D_{I} \\
\text { (VAr) }\end{array}$ & $\begin{array}{c}\mathbf{D}_{\mathrm{V}} \\
\text { (VAr) }\end{array}$ & $\begin{array}{c}\mathbf{S}_{\mathbf{H}} \\
(\mathbf{V A})\end{array}$ & & \\
\hline No & 228.0 & 228.0 & 3.6 & $1.6 \%$ & 158.8 & 78.4 & 138.1 & & & 17.2 & 17.3 & & 17.9 & 31.5 & & & 0.5 & 0060 & 171 \\
\hline Step 1 & 228.7 & & 3.6 & $1.6 \%$ & 134.3 & 66.4 & 116.8 & $176 \%$ & 30.7 & 14.4 & 14.5 & -0.1 & 15.2 & 26.7 & 26.7 & & 0.4 & & \\
\hline & 2285 & & 3.6 & & & 59.7 & 108.1 & & 28.2 & 12.9 & 13.0 & -0.1 & 13.6 & 24.7 & 24.7 & & 0.4 & & \\
\hline Step 3 & 229.2 & 229.2 & 3.6 & $1.6 \%$ & 110.5 & 53.3 & 96.8 & $182 \%$ & 25.3 & 11.4 & 11.5 & -0.1 & 12.2 & 22.2 & 22.2 & & 0.3 & 0.939 & 0.449 \\
\hline & 228.8 & & 3.8 & & 96.4 & & 84.4 & & & 9.8 & 9.9 & -0.1 & 10.7 & 19.3 & 19.3 & & 0.3 & & \\
\hline Step 5 & 228.9 & 228.9 & 3.7 & $1.6 \%$ & 82.6 & 39.9 & 72.3 & $181 \%$ & 18.9 & 8.1 & 8.2 & -0.1 & 01 & 16.5 & 16.5 & 0.1 & 0.3 & مO00 & 0421 \\
\hline Step 6 & 228.7 & 228.6 & 3.7 & $1.6 \%$ & 72.0 & 35.1 & 62.9 & & 16.5 & 6.9 & 6.9 & -0.1 & 8.0 & 14.4 & 14.4 & 0.1 & 0.2 & 0.865 & 0.418 \\
\hline & 228.9 & & 3.7 & & & & 46.2 & & & 5.0 & 5.0 & & 6.4 & 10.6 & 10.6 & & 0.2 & & 0.403 \\
\hline & 229.0 & 229.0 & 3.7 & $1.6 \%$ & 43.8 & 24.1 & 36.6 & $152 \%$ & 10.0 & 3.9 & 3.9 & 0.0 & 5.5 & 8.4 & 8.4 & 0.1 & 0.1 & 404 & 0281 \\
\hline Step 9 & 230.6 & 230.5 & 3.6 & $1.6 \%$ & 21.8 & 18.1 & 12.0 & $66 \%$ & & 1.0 & 1.0 & 0.0 & 4.2 & 2.8 & & 0.1 & 0.0 & 0.236 & 0.195 \\
\hline
\end{tabular}

Table 2. Power quality analysis of the measurements results for $49.5 \mathrm{~W}$ LED panel with $60 \mathrm{~W}$ ballast.

\begin{tabular}{|c|c|c|c|c|c|c|c|c|c|c|c|c|c|c|c|c|c|c|c|}
\hline \multirow{2}{*}{ Dimmer } & \multicolumn{4}{|c|}{ Voltage RMS values } & \multicolumn{4}{|c|}{ Current RMS values } & \multirow{2}{*}{$\begin{array}{c}\begin{array}{c}\text { App. } \\
\text { power }\end{array} \\
\text { S } \\
\text { (VA) }\end{array}$} & \multicolumn{3}{|c|}{$\begin{array}{c}\text { Active power } \\
\text { decomposition }\end{array}$} & \multicolumn{5}{|c|}{$\begin{array}{c}\text { Apparent power } \\
\text { decomposition }\end{array}$} & \multirow{2}{*}{$\cos \varphi_{1}$} & \multirow{2}{*}{$P F$} \\
\hline & $\begin{array}{c}\mathrm{V} \\
(\mathrm{V})\end{array}$ & $\begin{array}{l}V_{1} \\
(V)\end{array}$ & $\begin{array}{r}V_{H} \\
(V)\end{array}$ & $\mathrm{HD}_{\mathrm{V}}$ & $\begin{array}{c}\mathrm{I} \\
(\mathrm{mA})\end{array}$ & $\begin{array}{c}\mathbf{I}_{1} \\
(\mathbf{m A}) \\
\end{array}$ & $\begin{array}{c}\mathbf{I}_{\mathbf{H}} \\
(\mathbf{m A})\end{array}$ & THD $_{\text {I }}$ & & $\begin{array}{c}P \\
(\mathbf{W})\end{array}$ & $\begin{array}{l}P_{1} \\
(W)\end{array}$ & $\begin{array}{l}\mathbf{P}_{\mathrm{H}} \\
(\mathbf{W})\end{array}$ & $\begin{array}{c}S_{1} \\
(\mathrm{VA})\end{array}$ & $\mathbf{S}_{\mathbf{N}}$ & $\mathbf{D}_{\mathbf{I}}$ & $\mathbf{D}_{\mathrm{v}}$ & $\begin{array}{c}\mathbf{S}_{\mathbf{H}} \\
(\mathbf{V A}) \\
\end{array}$ & & \\
\hline No & 227.3 & 227.2 & 5.3 & $2,3 \%$ & 392.9 & 205.7 & & $163 \%$ & 89.3 & 44.6 & 44.8 & -0.2 & 46.7 & & & & 1.8 & 0.958 & 044 \\
\hline Step 1 & 27.4 & 227.3 & 5.3 & $2,3 \%$ & 339.9 & 174.9 & 291.4 & $167 \%$ & 77.3 & 37.7 & 37.8 & -0.2 & 39.7 & 66.3 & 00.2 & 0.9 & 1.5 & & 0.487 \\
\hline Step 2 & 227.5 & 227.4 & 5.3 & $2,3 \%$ & 312.9 & 158.8 & 269.6 & $170 \%$ & 71.2 & 34.1 & 34.2 & -0.1 & 36.1 & 61.3 & 61.3 & 0.8 & 1.4 & 0.948 & 0479 \\
\hline Step 3 & 27.1 & 227.0 & 5.3 & $2,3 \%$ & 271.8 & 138.7 & 233.7 & $169 \%$ & 61.7 & 29.5 & 29.6 & -0.1 & 31.5 & 53.1 & 53.1 & 0.7 & 1.2 & & 0.478 \\
\hline Step 4 & 227.0 & 226.9 & 5.2 & $2,3 \%$ & 244.5 & 122.7 & 211.5 & $172 \%$ & 55.5 & 25.9 & 26.0 & -0.1 & 27.8 & 48.0 & 48.0 & 0.6 & 1.1 & 0.934 & 0486 \\
\hline Step 5 & 227.7 & 227.7 & 5.3 & $2,3 \%$ & 205.9 & 102.9 & 178.4 & $173 \%$ & 46.9 & 21.3 & 21.3 & -0.1 & 23.4 & 40.6 & 40.6 & 0.5 & 1.0 & 0.911 & 0.453 \\
\hline & 228.1 & & & & & & & & & & & 0.0 & & 35.0 & & 0.5 & 0.8 & & 0.43 \\
\hline Step 7 & 228.3 & 228.2 & 5.1 & $2,2 \%$ & 144.9 & 71.2 & 126.2 & $177 \%$ & 33.1 & 13.6 & 13.7 & 0.0 & 16.3 & 28.8 & 28.8 & 0.4 & 0.6 & & 0.412 \\
\hline Step 8 & 228.0 & 227.9 & 5.2 & $2,3 \%$ & 110.9 & 57.4 & 94.9 & $165 \%$ & 25.3 & 9.9 & 9.9 & 0.0 & 13.1 & 21.6 & 21.6 & 0.3 & 0.5 & 0.756 & 0.392 \\
\hline Step 9 & 228.3 & 228.2 & & $2,2 \%$ & 57.7 & 37.9 & 43.5 & $115 \%$ & 13.2 & 2.0 & 1.9 & 0.1 & 8.6 & 9.9 & 9.9 & 0.2 & 0.2 & 0.221 & 0.152 \\
\hline
\end{tabular}

Figure 2. LED panel of $21 \mathrm{~W}$ without dimming: Current waveform and its harmonic spectrum.
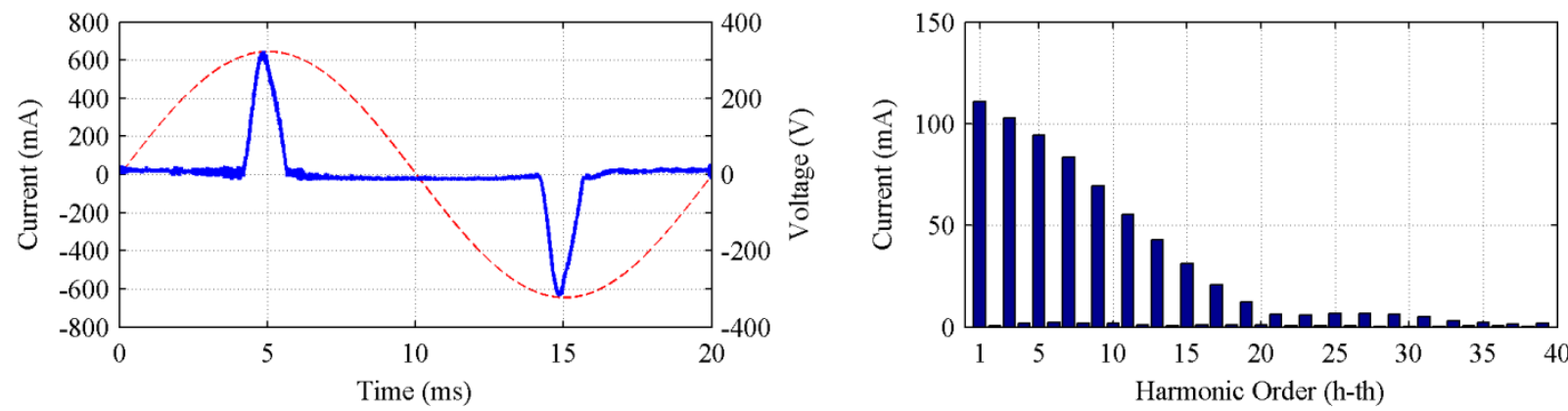
Figure 3. LED panel of $21 \mathrm{~W}$ with dimmer set to step 4: Current waveform and its harmonic spectrum.
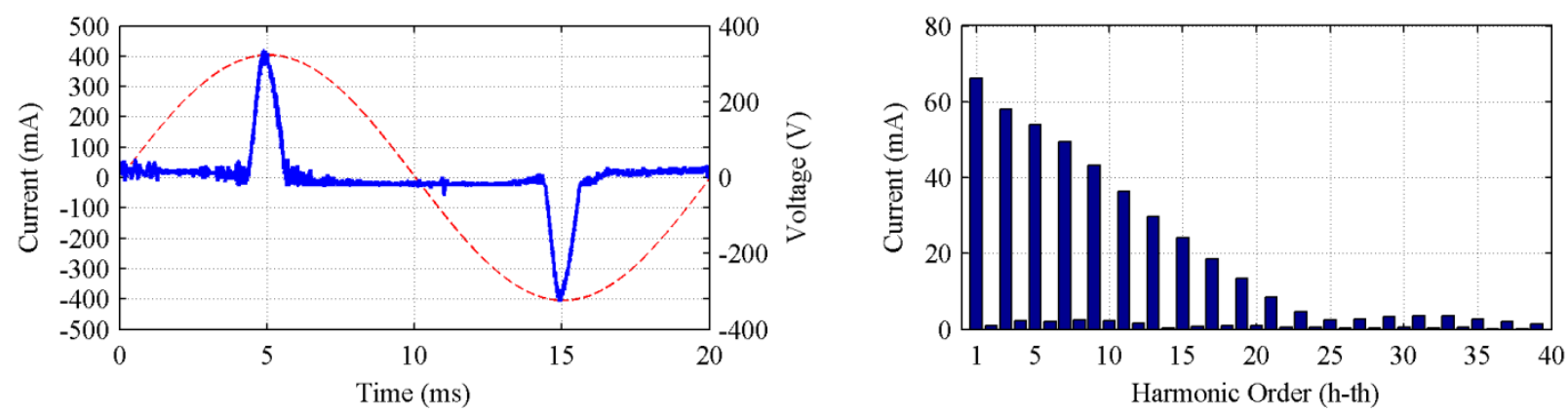

Figure 4. LED panel of $49.5 \mathrm{~W}$ without dimming: current waveform and its harmonic spectrum.
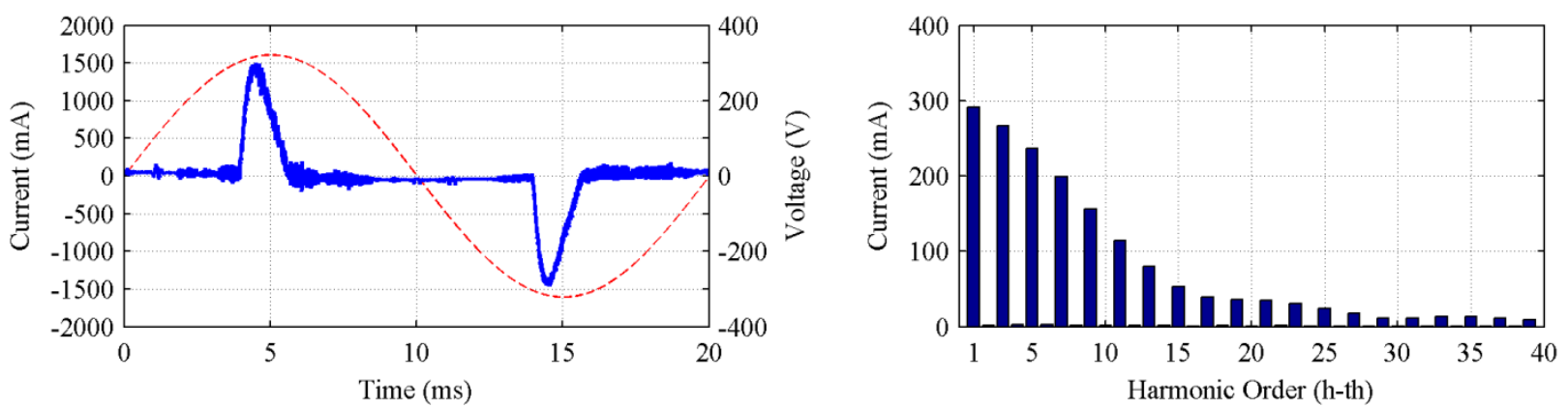

The power quality analysis leads to the considerations:

- The AC side current waveforms are affected by high distortion, while voltage is almost sinusoidal, as indicated by the THD indexes. Moreover, $T H D_{V}$ is not related to the load condition. In fact, voltage harmonics produced by the interaction between current harmonics and the very low grid equivalent impedance are negligible. The small value of $T H D_{V}$ is due only to the harmonic pollution already existing into the grid.

- Current waveforms indicate that the ballast input stage is based on a single phase Graetz bridge with a DC side smoothing capacitor; the pulse-type current waveform is related to this kind of circuit.

- The AC side current waveform is characterized by high derivative, and a significant part of the period when current is nil: these characteristics are reflected in a spectrum rich in harmonics, and harmonics with high or significant amplitude can be found up to about the 40th harmonic.

- The AC side current waveform changes in amplitude, but not in shape, with the dimming steps.

- The AC side voltage and current first harmonics have not a large phase shift. For the $60 \mathrm{~W}$ ballast, the small first harmonic in-quadrature capacitive component indicates the presence of capacitor on the ballast $\mathrm{AC}$ side acting as a simple EMC filter.

- $\cos \varphi_{1}$ and $P F$ reduce with the increase of dimming. Moreover, $P F$ is about half than $\cos \varphi_{1}$, indicating that harmonics in current waveform have a strong impact in reducing the quality in the energy conversion. 


\subsection{Experimental Tests on LED Spots}

LED spots are another kind of lighting devices based on several LEDs. Unlike LED panels, in LED spots the ballasts are embedded and no dimming system is provided. The layout of test arrangement for LED spots measurements is shown in Figure 5. In addition to electrical measurements, operating temperatures are also measured by using a thermal imaging camera. Experimental tests have been performed on four types of LED spots from different manufactures, hereafter called type A, B, C, and D.

The results of the power quality analysis are reported in Table 3.

Figure 5. (a) Test arrangement for LED spots monitoring survey; (b) LED Spots during test.

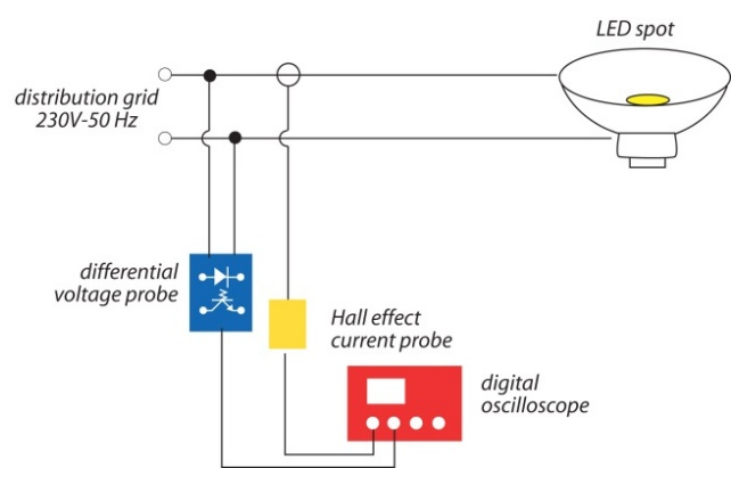

(a)

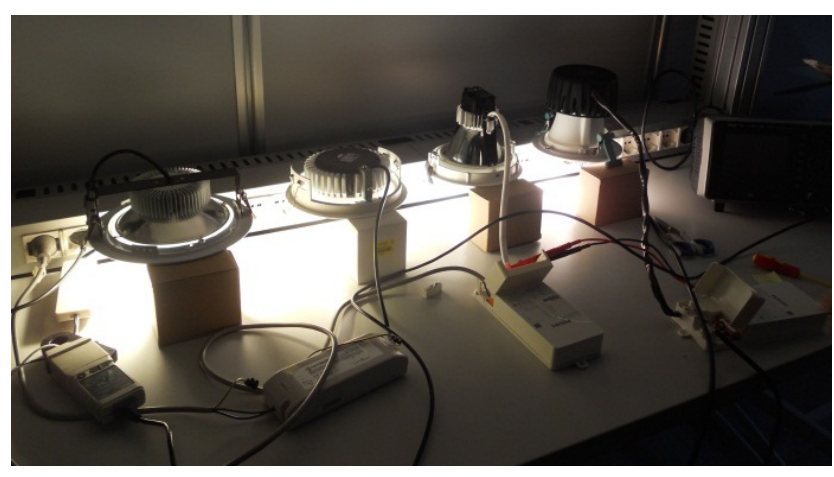

(b)

Table 3. Power quality analysis of the measurements results for LED Spots.

\begin{tabular}{|c|c|c|c|c|c|c|c|c|c|c|c|c|c|c|c|c|c|c|c|}
\hline \multirow{2}{*}{ Dimmer } & \multicolumn{4}{|c|}{ Voltage RMS values } & \multicolumn{4}{|c|}{ Current RMS values } & \multirow{2}{*}{$\begin{array}{c}\text { App. } \\
\text { power }\end{array}$} & \multicolumn{3}{|c|}{$\begin{array}{l}\text { Active power } \\
\text { decomposition }\end{array}$} & \multicolumn{5}{|c|}{$\begin{array}{c}\text { Apparent power } \\
\text { decomposition }\end{array}$} & \multirow{2}{*}{\multicolumn{2}{|c|}{$\cos \varphi_{1}$}} \\
\hline & $\begin{array}{c}\mathrm{V} \\
(\mathrm{V})\end{array}$ & $\begin{array}{l}V_{1} \\
(V)\end{array}$ & $\begin{array}{l}\mathrm{V}_{\mathrm{H}} \\
(\mathrm{V})\end{array}$ & THD $_{\mathrm{V}}$ & $\begin{array}{c}I \\
(\mathbf{m A}) \\
\end{array}$ & $\mathbf{I}_{1}$ & $\begin{array}{c}\mathbf{I}_{\mathrm{H}} \\
(\mathrm{mA})\end{array}$ & & & $\begin{array}{c}P \\
(W)\end{array}$ & $\begin{array}{c}\mathbf{P}_{1} \\
(\mathbf{W})\end{array}$ & $\begin{array}{l}P_{H} \\
(W)\end{array}$ & $\begin{array}{c}S_{1} \\
(\mathrm{VA})\end{array}$ & $\begin{array}{r}\mathrm{S}_{\mathrm{N}} \\
(\mathrm{VA})\end{array}$ & $\begin{array}{c}\mathbf{D}_{\mathrm{I}} \\
(\mathrm{VAr})\end{array}$ & $\begin{array}{c}\mathbf{D}_{\mathrm{V}} \\
\text { (VAr) }\end{array}$ & $\begin{array}{c}\mathbf{S}_{\mathrm{H}} \\
(\mathrm{VA}) \\
\end{array}$ & & \\
\hline & 2017 & 2216 & 3.6 & $1.6 \%$ & 208.4 & 2052 & 36.5 & $17.8 \%$ & 46.2 & 42.6 & 42.7 & -0.1 & 45.5 & 8.1 & 8.1 & 0.8 & 0.1 & 0.938 & 0.92 \\
\hline Type B & 221.8 & 2217 & 3.8 & $1.7 \%$ & 273.7 & 272. & 26.5 & $9.7 \%$ & 60.7 & 59.8 & 59.7 & 0.1 & 60.4 & 6.0 & 5.9 & & 0.1 & 0.988 & 0.98 \\
\hline Type C & 221.4 & & 3.8 & $1.7 \%$ & 193.1 & & 27.5 & $14.4 \%$ & 42.7 & 41.8 & 41.7 & 0.0 & 42.3 & 6.1 & 6.1 & 0.7 & 0.1 & 0.987 & 0.97 \\
\hline Type D & 220.5 & 220.4 & 3.8 & $1.7 \%$ & 145.6 & 144.4 & 18.9 & $13.1 \%$ & 32.1 & 30.5 & 30.5 & 0.0 & 31.8 & 4.2 & 4.2 & 0.6 & 0.1 & 0.959 & 0.950 \\
\hline
\end{tabular}

The power quality analysis leads to the considerations:

- The current waveforms are affected by a small amount of distortion, while voltage is almost sinusoidal, as indicated by the THD indexes. Also in this case, voltage harmonics due to harmonic current absorption are negligible and the small value of $T H D_{V}$ is related only to the harmonic pollution already existing into the grid.

- The embedded electronic ballasts adopt more sophisticated switching input circuits and control strategies with respect to the LED panels, allowing a current waveform as sinusoidal as possible. Current harmonics with significant amplitude can be found up to about the 10th harmonic.

- $\cos \varphi_{1}$ and $P F$ are very close to the unit value, indicating that voltage and current first harmonics have a little phase shift and harmonics in current waveform do not have a strong impact on the quality in the energy conversion [19]. 
Figures 6-9 show the current waveform, its harmonic spectrum and thermal image of each LED spot under test.

Figure 6. Type A LED spot: (a) Current waveform and its spectrum; (b) Thermal image.

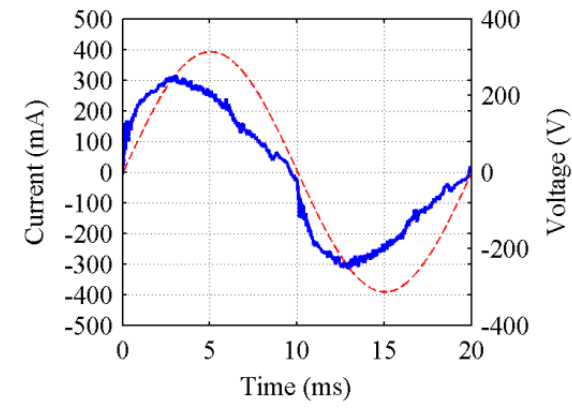

(a)

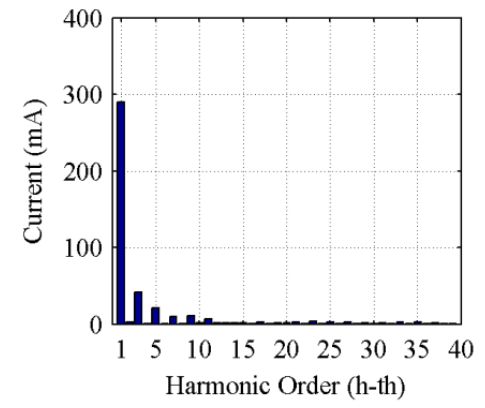

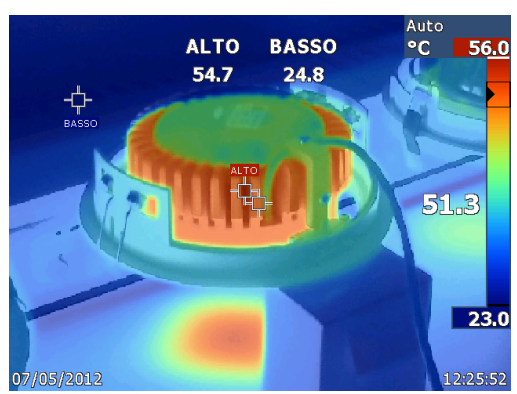

(b)

Figure 7. Type B LED spot: (a) Current waveform and its spectrum; (b) Thermal image.

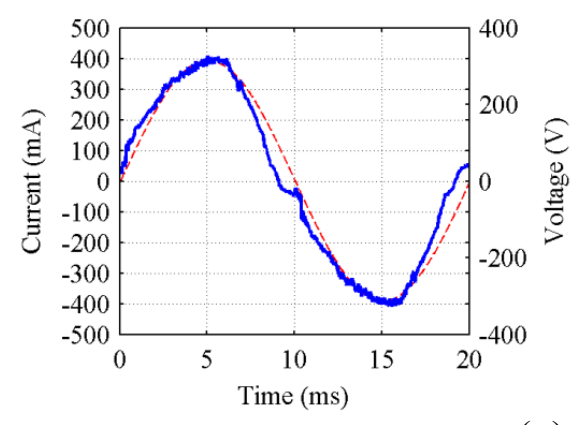

(a)

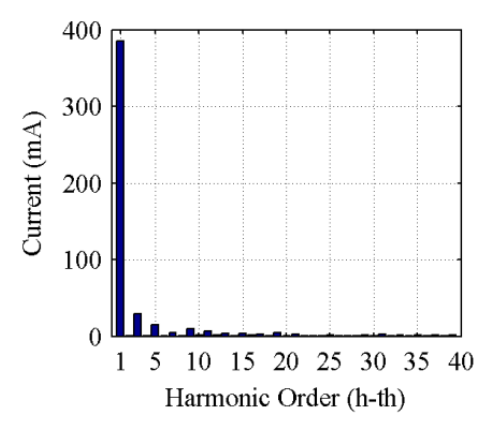

Figure 8. Type C LED spot: (a) Current waveform and its spectrum; (b) Thermal image.

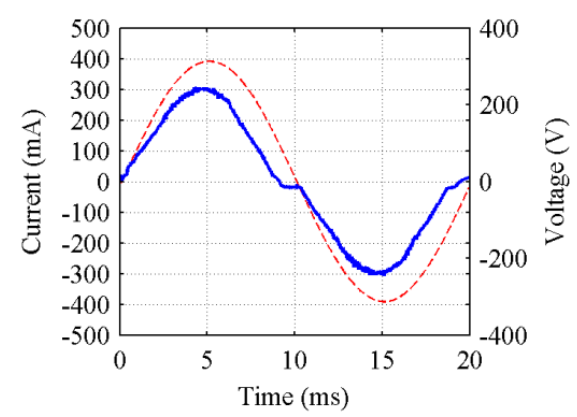

(a)

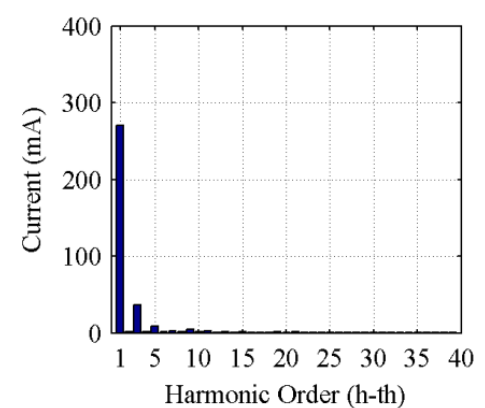

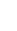

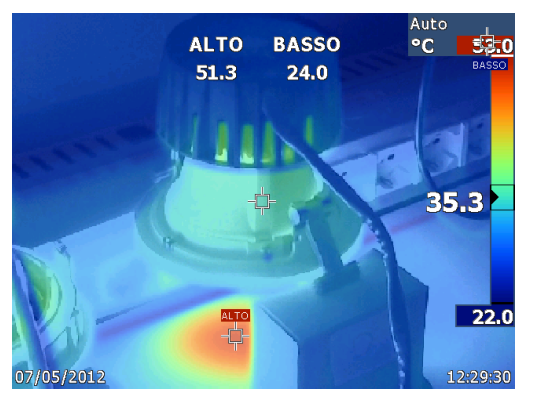

(b)

Figure 9. Type D LED spot: (a) current waveform and its spectrum; (b) thermal image.

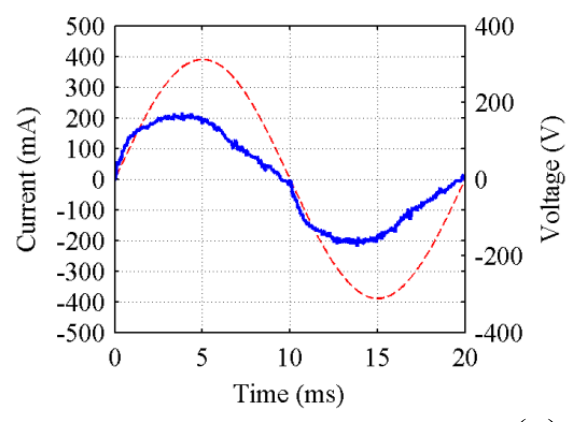

(a)

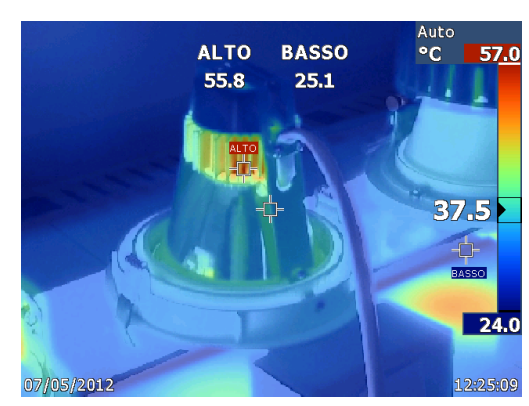

(b)

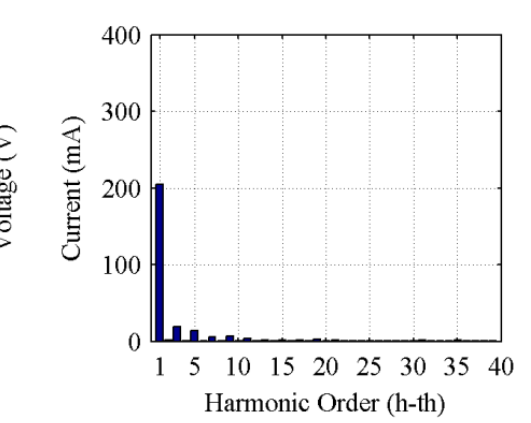

Harmonic Order (h-th)

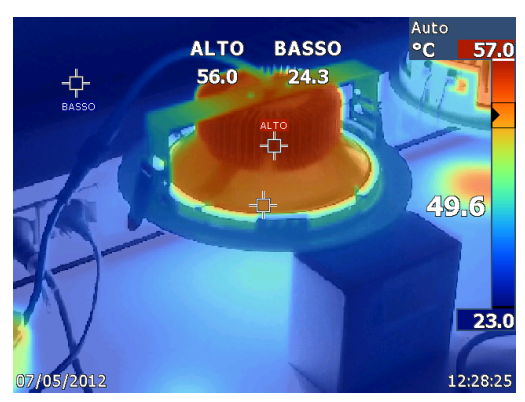

(b) 


\subsection{Experimental Tests on Compact Fluorescent Lamps}

Compact Fluorescent Lamps are widespread in indoor lighting application. Like for LED spots, also in compact fluorescent lamp ballasts are embedded and no external dimming system is provided. The layout of test arrangement for compact fluorescent lamps measurements is shown in Figure 10.

Figure 10. (a) Test arrangement for compact fluorescent lamp monitoring survey; (b) Compact fluorescent lamp during test.

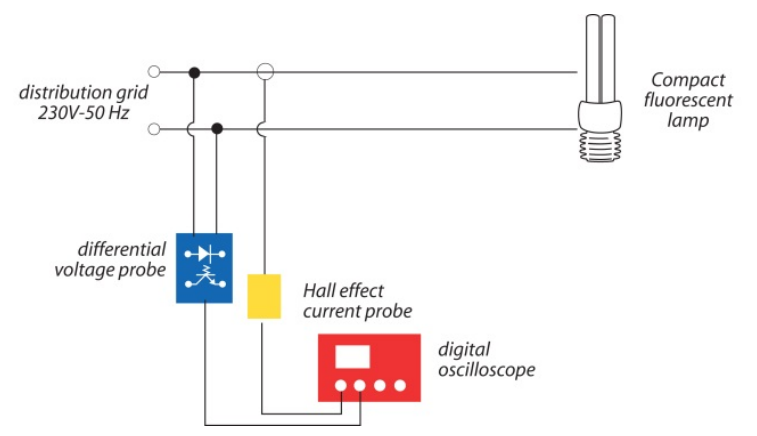

(a)

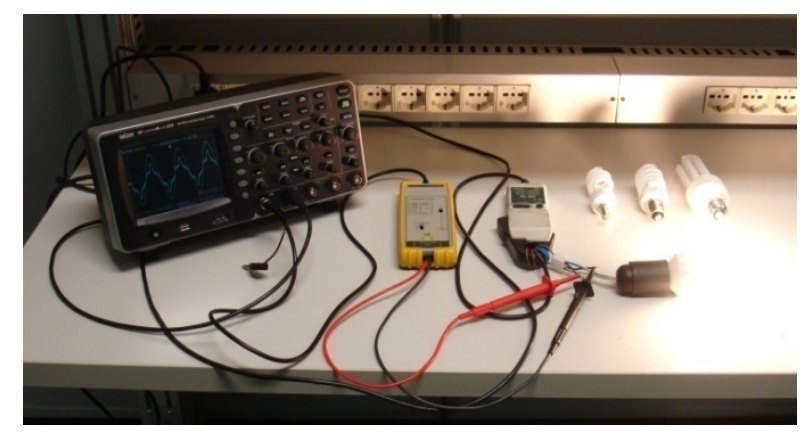

(b)

Experimental tests have been performed on four compact fluorescent lamps, two CFLs of earlier generation and two CFLs of new generation. The rated specifications are:

- CFL-A: $15 \mathrm{~W}$ new generation compact fluorescent lamp from manufacturer 1;

- CFL-B: $20 \mathrm{~W}$ new generation compact fluorescent lamp from manufacturer 1;

- CFL-C: $20 \mathrm{~W}$ earlier generation compact fluorescent lamp from manufacturer 2;

- CFL-D: $12 \mathrm{~W}$ earlier generation compact fluorescent lamp from manufacturer 3;

The results of the power quality analysis are reported in Table 4.

Table 4. Power quality analysis of the measurements results for compact fluorescent lamps.

\begin{tabular}{|c|c|c|c|c|c|c|c|c|c|c|c|c|c|c|c|c|c|c|c|}
\hline \multirow{2}{*}{ Type } & \multicolumn{4}{|c|}{ Voltage RMS values } & \multicolumn{4}{|c|}{ Current RMS values } & \multirow{2}{*}{$\begin{array}{c}\text { App. } \\
\text { power }\end{array}$} & \multicolumn{3}{|c|}{$\begin{array}{l}\text { Active Power } \\
\text { decomposition }\end{array}$} & \multicolumn{5}{|c|}{$\begin{array}{c}\text { Apparent power } \\
\text { decomposition }\end{array}$} & \multirow{2}{*}{\multicolumn{2}{|c|}{$\cos \varphi_{1}$}} \\
\hline & $\begin{array}{c}\mathrm{V} \\
(\mathrm{V}) \\
\end{array}$ & $\begin{array}{l}V_{1} \\
(V) \\
\end{array}$ & $\begin{array}{l}V_{H} \\
(V)\end{array}$ & THD $_{\mathrm{V}}$ & $\begin{array}{c}I \\
(\mathbf{m A}) \\
\end{array}$ & $\begin{array}{c}\mathrm{I}_{1} \\
(\mathrm{~mA}) \\
\end{array}$ & $\begin{array}{c}\mathbf{I}_{\mathbf{H}} \\
(\mathbf{m A}) \\
\end{array}$ & THD $_{\text {I }}$ & & $\begin{array}{c}\mathbf{P} \\
(\mathrm{W}) \\
\end{array}$ & $\begin{array}{c}\mathbf{P}_{1} \\
(\mathbf{W})\end{array}$ & $\begin{array}{r}\mathbf{P}_{\mathbf{H}} \\
(\mathbf{W})\end{array}$ & $\begin{array}{c}\mathrm{S}_{1} \\
(\mathrm{VA}) \\
\end{array}$ & $\begin{array}{r}S_{N} \\
(\mathbf{V A}) \\
\end{array}$ & $\begin{array}{c}\mathbf{D}_{\mathrm{I}} \\
(\mathrm{VAr}) \\
\end{array}$ & $\begin{array}{c}\mathbf{D}_{\mathrm{V}} \\
\text { (VAr) }\end{array}$ & $\begin{array}{c}\mathbf{S}_{\mathrm{H}} \\
(\mathrm{VA}) \\
\end{array}$ & & \\
\hline CFL-A & 225.9 & 225.9 & 3.6 & $1.6 \%$ & 66.0 & 64.2 & 15.0 & $23.3 \%$ & 14.9 & 14.3 & 14.3 & 0.0 & 14.5 & 3.4 & 3.4 & 0.2 & 0.1 & 0.986 & 0950 \\
\hline CFL-B & 225.4 & 225.4 & 3.4 & $1.5 \%$ & 92.8 & 90.0 & 22.8 & $25.4 \%$ & 20.9 & 20.1 & 20.2 & 0.0 & 20.3 & 5.2 & 5.1 & 0.3 & 0.1 & 0.995 & 0.962 \\
\hline CFL-C & 224.0 & 224.0 & 3.4 & $1.5 \%$ & 150.1 & 101.7 & 110.4 & $108.6 \%$ & 33.6 & 20.7 & 20.7 & -0.1 & 22.8 & 24.7 & 24.7 & 0.3 & 0.4 & 0.910 & 0.615 \\
\hline CFL-D & 223.6 & 223.6 & 3.3 & $1.5 \%$ & 84.1 & 58.0 & 61.0 & $105.1 \%$ & 18.8 & 11.6 & 11.7 & 0.0 & 13.0 & 13.6 & 13.6 & 0.2 & 0.2 & 0.900 & 0.618 \\
\hline
\end{tabular}

The power quality analysis leads to the considerations:

- The current waveforms are affected by distortion while voltage is almost sinusoidal, as indicated by the $T H D$ indexes. Also in this case, voltage harmonics due to harmonic current absorption are negligible and the small value of $T H D_{V}$ is related only to the harmonic pollution already existing into the grid [19]. 
- The new generation compact fluorescent lamps show smaller current distortion than the earlier generation ones: their $T H D_{I}$ is four times less than the $T H D_{I}$ of earlier generation compact fluorescent lamps.

- The AC side current waveform of earlier generation compact fluorescent lamps is characterized by high derivative and a significant part of the period when current is nil: these characteristics are reflected in a spectrum rich in harmonics, and harmonics with high or significant amplitude can be found up to about the 40th harmonic.

- Harmonics with significant amplitude in the AC side current waveform of new generation compact fluorescent lamps can be found up to about the 10th harmonic; the 5th harmonic is the higher. Moreover, the current waveforms show that the ballast input stage includes a valley-fill circuit for the passive correction of power factor. For the new generation compact fluorescent lamps, $\cos \varphi_{1}$ and $P F$ are very close to the unit value and $P F$ is a little lesser than $\cos \varphi_{1}$. This means that voltage and current first harmonics have a small phase shift and the significant harmonics in current waveform are few and small in amplitude. Therefore, current harmonics does not have a strong impact on the quality in the energy conversion. For the earlier generation compact fluorescent lamp, $\cos \varphi_{1}$ is less than in the new generation ones. Moreover, $P F$ is very low indicating that harmonics in current waveform have a strong impact in reducing the quality in the energy conversion.

Figures 11 and 12 show the current waveform and the harmonic spectrum of the new generation compact fluorescent lamps; Figures 13 and 14 show the current waveform and the harmonic spectrum of the earlier generation compact fluorescent lamps. The results here reported are in agreement with the results obtained by other Authors [17,18]. Furthermore, the new generation of CFLs shows a further improvement of the PQ behavior.

Figure 11. CFL-A: Current waveform and its harmonic spectrum.
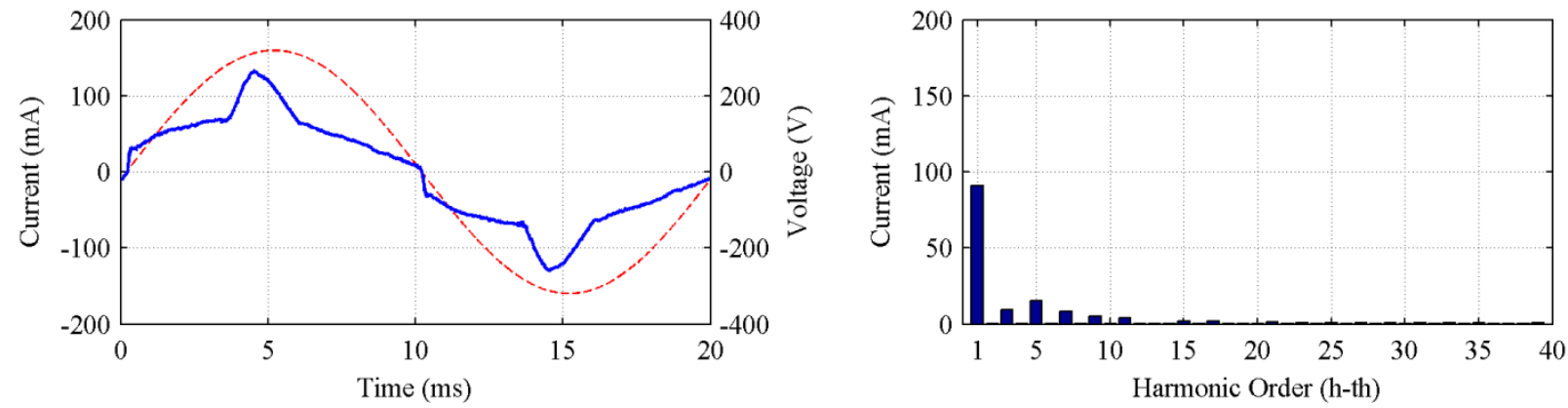

Figure 12. CFL-B: Current waveform and its harmonic spectrum.
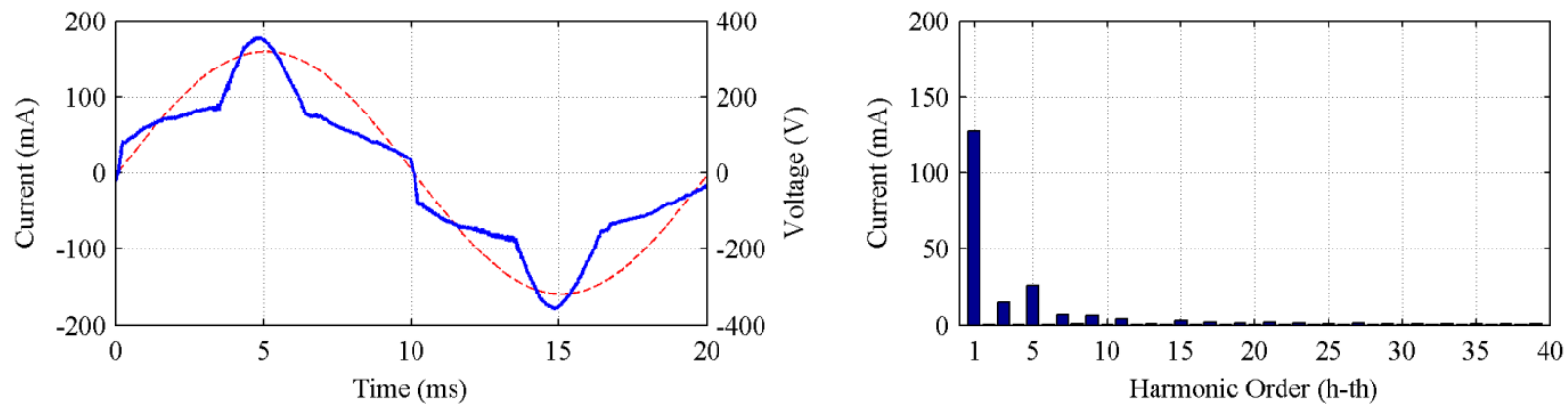
Figure 13. CFL-C: current waveform and its harmonic spectrum.
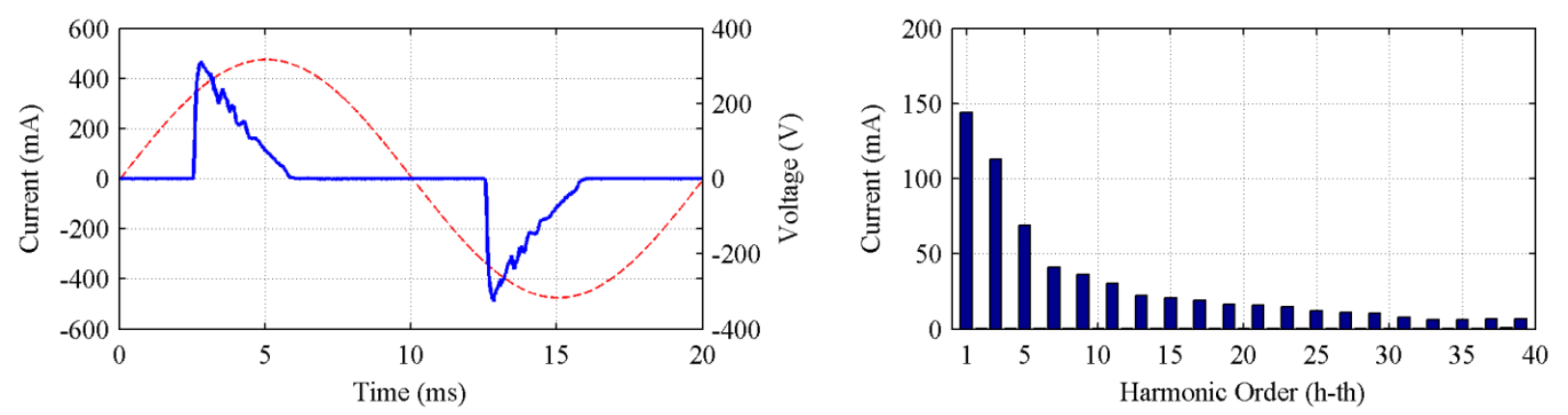

Figure 14. CFL-D: current waveform and its harmonic spectrum.
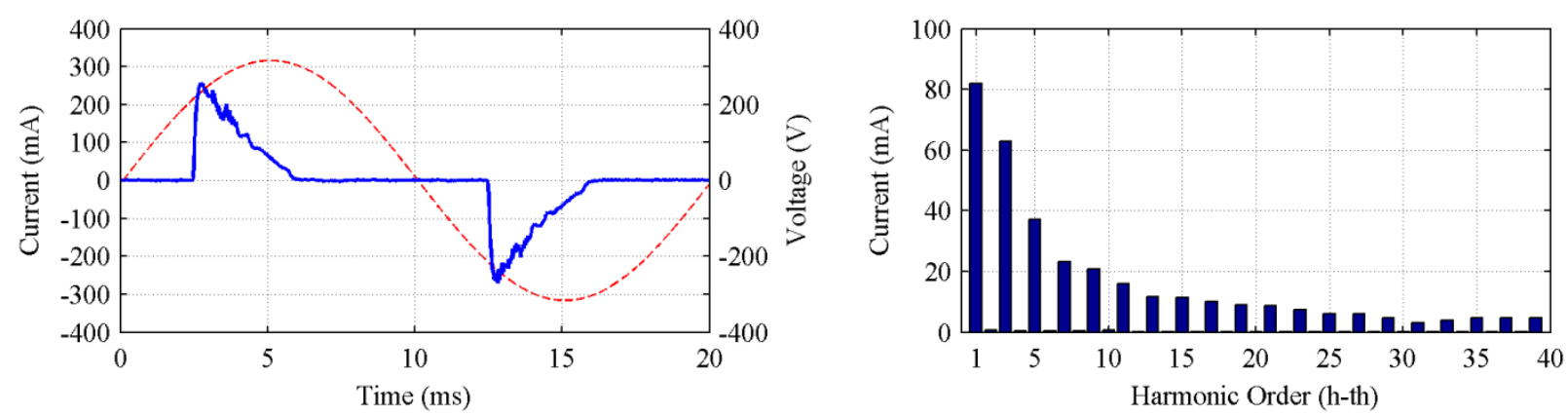

\section{Conclusions}

The paper deals with the harmonic characterization of indoor LEDs and Compact Fluorescent Lamps and their power supply systems. Several experimental results on harmonic generation of these lamps, which are currently being used for domestic, commercial and industrial lighting, are reported.

From the analysis of the obtained results, it is possible to conclude that all LEDs and CFLs generate harmonics due to the use of power electronic converter or ballast to drive them. The tested lamp $T H D_{I}$ is strongly dependent on the power supplier circuit topology and control strategy, and it is independent on the lamp technology and size.

It is also noted that different lamp manufacturers use several ballast technologies. Some power supply systems are based on very simple circuits - i.e., single phase Graetz bridge with a DC side smoothing capacitor-and are characterized by high current distortion while other ballasts includes different solutions suitable to improve PF. These solutions may be related to the circuit topology (i.e., passive power factor correction circuits or harmonic filters) and/or to the control strategy of the power converters (i.e., active PWM rectifiers).

The new generation of ballast uses filters and/or controlled switching circuit, like active rectifier, to reduce harmonic injection in the power system. In this case, the $P F$ can reach the unit value and the $T H D_{I}$ is very low, close to $10 \%$. Finally, the results here reported show an improvement of the PQ behavior of the new generation of CFLs. 


\section{References}

1. IEC EN 61000-3-2: Electromagnetic Compatibility, Part 3, Section 2, Limits for Harmonic Current Emissions (Equipment Input Current $\leq 16$ A per Phase), ed. 3; International Electrotechnical Commission (IEC), Geneva, Switzerland, 2011.

2. IEC EN 61000-4-7: Electromagnetic Compatibility (EMC), Testing and Measurement Techniques, General Guide on Harmonics and Interharmonics Measurements and Instrumentation, for Power Supply Systems and Equipment Connected Thereto; International Electrotechnical Commission, Geneva, Switzerland, 2002.

3. Voltage Characteristics in Public Distribution Systems, EN 50160; CENELEC, Brussels, Belgium, 1999.

4. Manzano, E.R.; Carlorosi, M.; Tapia Garzon, M. Performance and Measurement of Power Quality Due to Harmonics from Street Lighting Networks. In Proceedings of the Conference on Renewable Energies and Power Quality (ICREPQ'09), Valencia, Spain, 15-17 April 2009.

5. Pileggi, D.J.; Gulachenski, E.M.; Root, C.E.; Gentile, T.J.; Emanuel, A.E. The effect of modern compact fluorescent lights on voltage distortion. IEEE Trans. Power Deliv. 1993, 7, 1451-1459.

6. Dwyer, R.; Khan, A.K.; Mcgranaghan, M.; Tang, L.; Mccluskey, R.K.; Sung, R.; Houy, T. Evaluation of harmonic impacts from compact fluorescent lights on distribution systems. IEEE Trans. Power Syst. 1995, 11, 1772-1779.

7. Verderber, R.R.; Morse, O.C.; Alling, W.R. Harmonics from compact fluorescent lamps. IEEE Trans. Ind. Appl. 1993, 5, 670-674.

8. Pantaleone, G. Power electronics in public lighting systems: Are LEDs the only viable solution. Power Syst. Des. Eur. 2007, 4, 42-44. Available online: http://www.powersystemsdesign.com (accessed on 3 October 2012).

9. Soni, N.B.; Devendra, P. The transition to LED illumination: A case study on energy conservation. J. Theor. Appl. Inf. Technol. 2008, 4, 1083-1087.

10. Zografakis, N.; Karyotakis, K.; Tsagarakis, K.P. Implementation conditions for energy saving technologies and practices in office buildings: Part 1. Lighting. Renew. Sustain. Energy Rev. 2012, 16, 4165-4174.

11. Faranda, R.; Guzzetti, S.; Lazaroiu, C.; Leva, S. LEDs lighting: Two case studies. U.P.B. Sci. Bull. Ser. C 2011, 73, 199-210.

12. Dolara, A.; Faranda, R.; Guzzetti, S.; Leva, S. Power Quality in Public Lighting Systems. In Proceedings of the 14th International Conference on Harmonics and Quality of Power (ICHQP 2010), Bergamo, Italy, 26-29 September 2010.

13. Dolara, A.; Falvo, M.C.; Faranda, R.; Grasselli, U.; Leva, S. Lighting systems: Power Consumptions and Harmonics Monitoring Survey. In Proceedings of the 3rd International Conference on Clean Electrical Power: Renewable Energy Resources Impact (ICCEP 2011), Ischia, Italy, 14-16 June 2011; pp. 249-256.

14. Falvo, M.C.; Grasselli, U.; Lamedica, R.; Prudenzi, A. Harmonics Monitoring Survey on Office LV Appliances. In Proceedings of the 14th International Conference on Harmonics and Quality of Power (ICHQP 2010), Bergamo, Italy, 26-29 September 2010. 
15. Uddin, S.; Shareef, H.; Mohamed, A.; Hannan, M.A. An Analysis of Harmonics from LED Lamps. In Proceedings of the Asia-Pacific Symposium on Electromagnetic Compatibility (APEMC), Singapore, 21-24 May 2012; pp. 837-840.

16. Faranda, R.; Guzzetti, S.; Lazaroiu, G.C.; Leva, S. Refrigerating liquid prototype for LED's thermal management. Appl. Therm. Eng. 2012, 48, 155-163.

17. Monte, K.R.; Sen, P.K. Compact Fluorescent Lamps and Their Effect on Power Quality and Application Guidelines. In Proceedings of the Industry Applications Society Annual Meeting (IAS), Houston, TX, USA, 3-7 October 2010.

18. Rigo Mariani, R.; Rayudu, R.K.; Witherden, M.S.; Lai, E.M. Power Quality Indices of Compact Fluorescent Lamps for Residential Use-A New Zealand Study. In Proceedings of the IEEE TENCON 2010, Fukuoka, Japan, 21-24 November 2010; pp. 647-652.

19. Kiyak, I.A. Study on the working performance of dimming methods for single- and multichip power LEDs. Int. J. Photoenergy 2012, 2012, 513768:1-513768:8.

20. IEEE Std 1459-2000: IEEE Trial Use Standard Definitions for Measurement of Electric Power Quantities under Sinusoidal, Nonsinusoidal, Balanced, or Unbalanced Uonditions; Institute of Electrical and Electronics Engineers (IEEE): New York, NY, USA, 2000.

(C) 2012 by the authors; licensee MDPI, Basel, Switzerland. This article is an open access article distributed under the terms and conditions of the Creative Commons Attribution license (http://creativecommons.org/licenses/by/3.0/). 